\title{
Alcohol consumption and outcome of pregnancy
}

\author{
JEANE ANN GRISSO,${ }^{1}$ EVE ROMAN,${ }^{1}$ HAZEL INSKIP,${ }^{1}$ VALERIE BERAL,${ }^{1}$ AND \\ JOHN DONOVAN ${ }^{2}$
}

From the London School of Hygiene and Tropical Medical, ${ }^{1}$ London WC1E 7HT, UK, and Department of Health, ${ }^{2}$ Woden 2606, Canberra, Australian Capital Territory

SUMMARY In a prospective study 1256 pregnant women at their first antenatal visit were asked if they drank alcohol every day, occasionally, or not at all, both at that time and before the diagnosis of pregnancy. There were no significant differences, among the three alcohol groups, in the proportions having miscarriages, perinatal deaths, congenital anomalies, or premature births. Women who reported drinking every day before pregnancy was diagnosed had heavier babies than those who did not drink at all, but there were no differences in mean birth weight according to alcohol use at the first antenatal visit. There were statistically significant differences among the three groups in important background characteristics, such as social class, age, smoking, and marital status. When adjustment was made for these factors, both occasional and daily consumption of alcohol before pregnancy appeared to have significantly positive effects on birth weight. These results illustrate the difficulty of evaluating the effects of alcohol in observational studies, and imply a need for caution in attributing either negative or positive effects of alcohol on the outcome of pregnancy.

Epidemiological studies of the consequences of maternal drinking during pregnancy confirm clinical reports that alcohol in high doses is teratogenic. ${ }^{1-3}$ There is, however, controversy concerning the effects of drinking at lower levels, which are often described as "social." Some workers have suggested that alcohol consumed at such levels is associated with intrauterine growth retardation, increased risk of congenital anomalies, behavioural problems in infants and children, and increased risk of fetal wastage..$^{4-10}$ Others have reported no such associations ${ }^{11-14}$ One explanation for the conflicting results is that it is difficult to adjust for the effects of all potentially confounding factors, such as smoking and social class. ${ }^{15}$ It has also been suggested that alcohol has different effects when consumed at different periods during pregnancy. ${ }^{56-18}$ Using information collected prospectively on the social and personal characteristics of 1256 pregnant women, the relation between alcohol consumption, birth weight, and fetal and perinatal loss was investigated.

\section{Data and methods}

In 1972-3 as part of a controlled clinical trial to assess the relation between antismoking advice given in pregnancy and birth weight consecutive series of women who contacted one of three London maternity units for their first antenatal visit were sent a reply paid postal questionnaire with the hospital administrative documents. Details of the main study were described by Donovan. ${ }^{19}$ All information was obtained on or before the first antenatal visit. Women were asked to supply details of their drinking habits before pregnancy and at the time of their first antenatal visit. For both periods they were asked whether they drank alcohol occasionally, every day, or not at all. Other information requested included parity, maternal age, the use of tobacco before and during pregnancy, and the occupations of their partners and themselves. Using the Registrar General's Classification of Occupations ${ }^{20}$ the women were grouped into social classes according to their partner's occupation. Pregnancy outcome information and birth weights of infants were taken from hospital records.

There were 1197 singleton live births (of which 11 were neonatal deaths) and 10 stillbirths. Forty nine women were known to have miscarried after their first antenatal visit. Seventeen pairs of twins were excluded from the analysis. Except when looking at birth outcome, the results presented here refer only to those 1197 women who had singleton live births. 


\section{Results}

Women who drank every day before pregnancy was diagnosed had babies who were, on average, significantly heavier than those who did not drink at all $(p<0.05)$ (table 1$)$. The mean birth weight of babies born to mothers who drank occasionally lay between the other two groups. There were no significant differences in mean birth weight according to alcohol use at the first antenatal visit nor were there significant differences in the proportion who had miscarriages, perinatal deaths, congenital anomalies, or premature births (table 2 ).

Table 1 Birth weight of singleton live births according to alcohol use of mother

\begin{tabular}{llcc}
\hline & \multicolumn{3}{l}{ Alcohol use before pregnancy } \\
\cline { 2 - 4 } & $\begin{array}{l}\text { None } \\
(n=224)\end{array}$ & $\begin{array}{c}\text { Occasional } \\
(n=872)\end{array}$ & $\begin{array}{l}\text { Every day } \\
(n=101)\end{array}$ \\
\hline $\begin{array}{l}\text { Mean birthweight(g) } \\
\pm \text { standard error }\end{array}$ & 3155 & 3237 & 3322 \\
Proportion weighing & 35 & 18 & 57 \\
2500 g or less & & & \\
\hline
\end{tabular}

Table 2 Pregnancy outcome according to alcohol use

\begin{tabular}{lccc}
\hline & \multicolumn{3}{l}{ Alcohol use before pregnancy } \\
\cline { 2 - 4 } & None & Occasional & Every day \\
\hline Miscarriages & $9(3.8 \%)$ & $38(4 \cdot 1 \%)$ & $2(1.9 \%)$ \\
$\begin{array}{l}\text { Perinatal deaths: } \\
\text { Stillbirths }\end{array}$ & 3 & 6 & 1 \\
$\begin{array}{l}\text { Neonatal deaths } \\
\text { Total }\end{array}$ & 4 & 8 & 0 \\
$\begin{array}{l}\text { Proportion born prematurely } \\
\text { (before 37 weeks) }\end{array}$ & $7(3.1 \%)$ & $14(1.6 \%)$ & $1(1.0 \%)$ \\
$\begin{array}{l}\text { Proportion of live born with } \\
\text { congenital malformations }\end{array}$ & $8.5 \%$ & $7.5 \%$ & $5.0 \%$ \\
\hline
\end{tabular}

There were important differences in background characteristics (table 3). Women who drank every day tended to be older, primiparous, and to smoke more cigarettes. In addition, most partners of women who drank daily were from social classes I and II, none were from social classes IV and V, and this pattern differed significantly from the other two groups $(p<0 \cdot 01)$. Within each social class there was a consistent, but non-significant, trend for mean birth weight to increase with increasing alcohol use (table 4). Among women who did not report a partner's occupation, however, this relation was reversed.

To adjust for the effects of parity, social class, maternal age, and cigarette smoking on birth weight, multiple linear regression was used. Smoking and
Table 3 Characteristics of women according to alcohol use before pregnancy

\begin{tabular}{|c|c|c|c|}
\hline & \multicolumn{3}{|l|}{ Alcohol use } \\
\hline & $\begin{array}{l}\text { None } \\
(n=224)\end{array}$ & $\begin{array}{l}\text { Occasional } \\
(n=872)\end{array}$ & $\begin{array}{l}\text { Every day } \\
(n=101)\end{array}$ \\
\hline $\begin{array}{l}\text { Partner's social class }(\%) \\
\text { No partner's occupation recorded } \\
\text { Social classes I-II } \\
\text { Social class III } \\
\text { Social classes IV-V } \\
\text { Othert }\end{array}$ & $\begin{array}{r}7 \% \\
21 \% \\
43 \% \\
25 \% \\
5 \%\end{array}$ & $\begin{array}{r}16 \% \\
26 \% \\
39 \% \\
15 \% \\
4 \%\end{array}$ & $\begin{array}{r}23 \% \\
57 \% \\
18 \% \\
0 \% \\
2 \%\end{array}$ \\
\hline $\begin{array}{l}\text { Cigarette consumption: } \\
\text { Proportion who smoked } \\
\text { (at first antenatal visit) } \\
\text { Proportion of smokers } \\
\text { smoking } 2 \text { packs a day }\end{array}$ & $\begin{array}{r}62 \% \\
8 \%\end{array}$ & $\begin{array}{r}66 \% \\
8 \%\end{array}$ & $\begin{array}{l}63 \% \\
19 \%\end{array}$ \\
\hline $\begin{array}{l}\text { Primipara (\%): } \\
\text { Age at last menstrual period } \\
\text { (years } \pm \text { standard error) } \\
\text { Proportion single } \\
\text { Proportion with } 1 \text { or more previous } \\
\text { miscarriages (women with previous } \\
\text { pregnancies) } \\
\text { Mean gestational age (days) } \\
\pm \text { standard error }\end{array}$ & $\begin{array}{l}42 \% \\
25 \pm 0 \cdot 3 \\
10 \% \\
25 \% \\
280 \pm 1 \cdot 4\end{array}$ & $\begin{array}{l}58 \% \\
25 \pm 0 \cdot 2 \\
16 \% \\
22 \% \\
280 \pm 0.6\end{array}$ & $\begin{array}{l}66 \% \\
26 \pm 0.4 \\
20 \%\end{array}$ \\
\hline
\end{tabular}

Table 4 Mean birth weight $(g)^{*}$ of infants according to mother's alcohol use and social class

\begin{tabular}{|c|c|c|c|}
\hline & \multicolumn{3}{|c|}{ Alcohol use before pregnancy } \\
\hline & None & Occasional & Every day \\
\hline \multicolumn{4}{|l|}{ Partner's social class: } \\
\hline Social classes I-II & $\begin{array}{c}3166 \pm 53 \\
(n=47)\end{array}$ & $\begin{array}{r}3292 \pm 32 \\
(n=229)\end{array}$ & $\begin{array}{c}3354 \pm 68 \\
(n=58)\end{array}$ \\
\hline Social class III & $\begin{array}{c}3149 \pm 63 \\
(n=96)\end{array}$ & $\begin{array}{r}3253 \pm 29 \\
(n=338)\end{array}$ & $\begin{array}{c}3588 \pm 157 \\
(n=18)\end{array}$ \\
\hline Social classes IV-V & $\begin{array}{c}3128 \pm 74 \\
(n=55)\end{array}$ & $\begin{array}{r}3223 \pm 55 \\
(n=134)\end{array}$ & $(n=0)$ \\
\hline No partner's occupation recorded & $\begin{array}{c}3132 \pm 74 \\
(n=16)\end{array}$ & $\begin{array}{r}3140 \pm 48 \\
(n=135)\end{array}$ & $\begin{array}{c}3021 \pm 123 \\
(n=23)\end{array}$ \\
\hline Othert & $\begin{array}{c}3329 \pm 198 \\
(n=9)\end{array}$ & $\begin{array}{c}3176 \pm 96 \\
(n=33)\end{array}$ & $\begin{array}{c}3132 \pm 127 \\
(n=2)\end{array}$ \\
\hline
\end{tabular}

* Standard error.

†Includes students, unemployed, and members of armed forces.

parity had a significant effect but, surprisingly, age and social class did not. After adjusting for these factors, both occasional $(p<0 \cdot 05)$ and daily $(p<0.01)$ consumption of alcohol had significantly positive effects on birth weight.

The mean birth weight of babies born to those who changed their alcohol consumption by the time of the first antenatal visit was examined (table 5). No clear pattern emerged, although those who had drunk every day and stopped completely had, on average, the heaviest babies. When change in alcohol consumption was added to the multiple regression 
Table 5 Mean birth weight $(\mathrm{g})^{*}$ of infants according to mother's alcohol use

\begin{tabular}{|c|c|c|c|c|}
\hline & \multirow[b]{2}{*}{ None } & \multicolumn{3}{|c|}{ Alcohol use at first antenatal visit } \\
\hline & & Occasional & Every day & Total \\
\hline \multicolumn{5}{|c|}{$\begin{array}{l}\text { Alcohol before } \\
\text { pregnancy: }\end{array}$} \\
\hline None & $\begin{array}{r}3163 \pm 34 \\
(n=214)\end{array}$ & $\begin{array}{l}3009 \pm 308 \\
(n=9)\end{array}$ & $\begin{array}{c}2722 \pm 0 \\
(n=1)\end{array}$ & $\begin{array}{r}3155 \pm 35 \\
(n=224)\end{array}$ \\
\hline Occasional & $\begin{array}{r}3235 \pm 36 \\
(n=209)\end{array}$ & $\begin{array}{c}3237 \pm 21 \\
(n=661)\end{array}$ & $\begin{array}{l}3342 \pm 342 \\
(n=2)\end{array}$ & $\begin{array}{r}3237 \pm 19 \\
(n=872)\end{array}$ \\
\hline Every day & $\begin{array}{c}3602 \pm 180 \\
(n=31)\end{array}$ & $\begin{array}{c}3334 \pm 85 \\
(n=41)\end{array}$ & $\begin{array}{c}3233 \pm 83 \\
(n=47)\end{array}$ & $\begin{array}{r}3321 \pm 57 \\
(n=101)\end{array}$ \\
\hline Total & $\begin{array}{r}3211 \pm 35 \\
(n=436)\end{array}$ & $\begin{array}{r}3240 \pm 20 \\
(n=711)\end{array}$ & $\begin{array}{c}3227 \pm 79 \\
(n=50)\end{array}$ & \\
\hline
\end{tabular}

$*$ Standard error.

model, neither reducing nor increasing consumption had a significant effect on birth weight

\section{Discussion}

The data presented here have the advantage that since the information was collected early in pregnancy, there is no possibility that reports of alcohol consumption could be altered by knowledge of the outcome of pregnancy. Information was only available, however, about three categories of drinking, and so the quantity of alcohol in each drink, the number of drinks consumed on each occasion, and the type of beverage could not be considered. Details of drinking habits were not obtained after the first antenatal visit, and hence no evaluation can be made of changes later in pregnancy. Furthermore, as in all epidemiological studies to date, the estimate of alcohol use was from self report, the accuracy of which probably varies with the level of drinking. ${ }^{15}$ Simple frequency data as presented here, however, are probably relatively accurate, if somewhat crude, measures of consumption. ${ }^{21}$

Taken at face value the findings presented here seem to imply that drinking daily at the time of conception is beneficial to the outcome of pregnancy. These results are in apparent disagreement with those reporting an increased risk of low birth weight and intrauterine growth retardation with increasing alcohol consumption. ${ }^{45}$ Some workers have, however, noted no deleterious effects unless consumption exceeded two drinks daily, ${ }^{11}{ }^{13}$ and others have found no association between drinking habits and birth weight. ${ }^{12}{ }^{14}$ Moreover, Kuzma and colleagues reported that the volume of aicohol consumed did not relate significantly to adjusted birth weight, although the components of maternal drinking behaviour had some influence. ${ }^{21}$ They noted that the frequency of wine and spirits drinking was significantly and positively correlated with infant birth weight whereas beer drinking appeared to have a negative effect. Similarly Kaminski et al found that low birth weight was related primarily to heavy beer consumption as opposed to wine drinking. ${ }^{13}$ Unfortunately, in our study no information on type of beverage was obtained. It may be that the women who reported daily drinking, who were primarily from social classes I-II, drank mostly wine or spirits rather than beer.

The social class distribution of our sample is similar to that reported for other studies in England and Wales. Wright and colleagues found that twice as many heavy drinkers were from social classes I and II rather than social classes III to V. ${ }^{18}$ The report of the General Household Survey of 1978 showed that abstinence was twice as common among women whose husbands were manual workers compared with non-manual workers and the proportion of frequent to light drinkers was higher among the wives of non-manual workers. ${ }^{22}$ These differences in social class distribution do not explain our results, however, since within each social class group women who reported drinking tended to have heavier babies, and ${ }$ N $_{\text {N }}$ adjusting for social class differences did not alter the $\vec{O}_{\mathrm{N}}^{\mathrm{L}}$ positive association.

Our results clearly show the difficulty of evaluating the effects of alcohol in observational studies. Human drinking is an extremely complex behaviour. Many factors may influence a women to abstain or change her drinking patterns. Social and ethnic factors may affect the level of drinking, how it ise reported, and the type of beverage consumed. One? should be cautious in attributing either negative or positive effects of alcohol on outcome of pregnancy, particularly at levels of drinking that could be defined as "social." In view of this the current recommendation ${ }^{2324}$ of total abstinence immediately before and during pregnancy should, perhaps, be investigated further.

This study was supported in part by the Tobacco Research Council and the Medical Research Council. Dr Jeane Ann Grisso is a Milbank Memorial Scholar.

\section{References}

${ }^{1}$ Jones KL, Smith DW, Streissguth AP, Myrianthopoulos NC. Patterns of malformation in offspring of chronic alcoholic women. Lancet 1973; ii: 1267-71.

${ }^{2}$ Jones KL, Smith DW. The fetal alcohol syndrome. Teratology 1975; 12: 1-10.

${ }^{3}$ Streissguth AP, Landesman-Dwyer S, Martin JC, Smith DW. Teratogenic effects of alcohol in humans and laboratory animals. Science 1980; 209: 353-61. 
4 Olegard R, Sabel G, Aronson M, et al. Effects on the child of alcohol abuse during pregnancy. Acta Paediatr Scand 1979; 275 (suppl): 112-21.

${ }^{5}$ Little RE. Moderate alcohol use during pregnancy and decreased infant birth weight. Am J Public Health 1977; 67: 1154-6.

${ }^{6}$ Streissguth AP, Martin DC, Martin JC, Barr HM. The Seattle longitudinal prospective study on alcohol and pregnancy. Neurobehav Toxicol Teratol 1981; 3: 22333.

${ }^{7}$ Harlap S, Chiono PH. Alcohol, smoking, and incidence of spontaneous abortions in the first and second trimester. Lancet 1980; ii: 173-6.

${ }^{8}$ Kline J, Shrout P, Stein Z, Susser M, Warburton D. Drinking during pregnancy and spontaneous abortion. Lancet 1980; ii: 176-80.

${ }^{9}$ Landesman-Dwyer S, Ragozin AS, Little RE. Behavioural correlates of prenatal alcohol exposure: a four year follow up study. Neurobehav Toxicol Teratol 1981; 3: 187-93.

${ }^{10}$ Streissguth AP, Barr HM, Martin DC, Herman CS. Effects of maternal alcohol nicotine, and caffeine use during pregnancy on infant mental and motor development at eight months. Alcoholism: Clinical and Experimental Research 1980; 4: 152-64.

${ }^{1}$ Ouellette EM, Rosett HL, Rosman NP, Weiner L. Adverse effects on offspring of maternal alcohol abuse during pregnancy. $N$ Engl J Med 1977; 297: 528-30.

${ }^{12}$ Tennes K, Blackard C. Maternal alcohol consumption, birthweight, and minor physical anomalies. Am J Obstet Gynecol 1980; 138: 774-8.

${ }^{13}$ Kaminski M, Franc M, Lebouvier M, du Mazaubrun C, Rumeau-Rouquette $C$. Moderate alcohol use and pregnancy outcome. Neurobehav Toxicol Teratol 1981 3: $173-81$.

${ }^{14}$ Pettersson F, Melander S. Prediction of birthweight: results of a multiple regression analysis. Ups J Med Sci 1975; 80: 135-40.

${ }^{15}$ Little RE. Epidemiologic and experimental studies in drinking and pregnancy: the state of the art. Neurobehav Toxicol Teratol 1981; 3: 163-7.

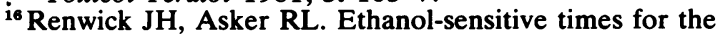
human conceptus. Early Hum Dev 1983; 8: 99-111.

${ }^{17}$ Rosett HL, Weiner L, Zuckerman B, McKinlay S, Edeling C. Reduction of alcohol consumption during pregnancy with benefits to the newborn. Alcoholism: Clinical and Experimental Research 1980; 4: 174-84.

${ }^{18}$ Wright JT, Waterson EJ, Barrison TG, et al. Alcohol consumption, pregnancy, and low birthweight. Lancet 1983; i: 663-5.

${ }^{19}$ Donovan JW. Randomised controlled trial of anti-smoking advice in pregnancy. Br J Prev Soc Med 1977; 31: 6-12.

${ }^{20}$ Office of Population Censuses and Surveys. Registrar General's classification of occupations. London: HMSO, 1970.

${ }^{21}$ Kuzma JW. Sokol J. Maternal drinking behaviour and decreased intrauterine growth. Alcoholism: Clinical and Experimental Research 1982; 6: 396-401.

${ }^{22}$ Office of Population Censuses and Surveys. Social Survey Division. General houshold survey 1978. Series GHS No 8. London: HMSO, 1980.

${ }^{23} \mathrm{U}$ S Surgeon General. Surgeon General's advice on alcohol and pregnancy. F D A Drug Bull 1981; 11: 9-10.

${ }^{24}$ Royal College of Psychiatrists. Alcohol and alcoholism. Bulletin of the Royal College of Psychiatrists 1982; 6: 69. 